\title{
Correspondence
}

\begin{abstract}
We welcome letters to the Editor concerning articles which have recently been published. Such letters will be subject to the usual stages of selection and editing; where appropriate the authors of the original article will be offered the opportunity to reply.
\end{abstract}

Letters should normally be under 300 words in length, double-spaced throughout, signed by all authors and fully referenced. The edited version will be returned for approval before publication.

\section{Is titanium so bad?}

Sir,

I read with interest the article in the July 2001 issue by Bowditch and Villar ${ }^{1}$ entitled 'Is titanium so bad?'. They present data which may offset the current criticism of titanium alloy total hip implants. Although the follow-up of their patients may be too short to give their claims solid grounds, their guarded enthusiasm is worth considering.

I hold the dubious distinction of having been the surgeon who participated in the design of the first titanium alloy total hip prosthesis implanted in the USA. ${ }^{2}$ Six years after the first implantation we published a preliminary report. At that time we concluded that the results from the new implant were as good as those which we had obtained with the Charnley prosthesis. ${ }^{3}$ Nothing suggested at that point that the implant would behave differently from the Charnley. Parallel investigations were carried out in our laboratories by McKellop et $\mathrm{al}^{4}$ who demonstrated the excellent wear properties of the material against polyethylene. Under clean laboratory conditions the wear of polyethylene against titanium was as good as or even slightly better than that against stainlesssteel and cobalt-chrome alloys.

However, as the clinical follow-up was extended by additional years, we noticed a gradual increase in the incidence of radiological changes which had not been apparent in the first six years. ${ }^{5-7}$ The rate of wear of the polyethylene liner had increased, the incidence of radiolucent lines around the femoral component became more evident, and revision surgery became more frequent. Metallosis, however, was not identified in 17 failed implants. The increased rate of clinical and radiological failures eventually convinced us that the clinical use of the monoblock titanium-alloy prosthesis could no longer be justified. The implant was modified to accommodate a modular cobalt-chrome head. The results obtained with the modified implant have not yet been documented.

The fact that I have on record a number of monoblock titanium implants which have remained free from undesirable radiological changes for as long as 25 years, raises a number of questions as to why the rate of failure of cemented titanium implants is greater. It is not because of inferior wear properties, since they are good. If the wear properties had been poor, all the implanted titanium prostheses would have failed after a period of time. A clear explanation is required for the fact that hybrid titanium total hip implants (a cemented stem, an uncemented acetabulum) perform worse than those cemented at both ends of the joint. The same is true for implants which have a cemented metal-backed acetabulum.

(C2001 British Editorial Society of Bone and Joint Surgery 0301-620X/02/613594 \$2.00

J Bone Joint Surg [Br] 2002;84-B:931-2.
Based on our clinical and laboratory studies we have concluded that an explanation for the higher failure of cemented titanium prostheses is the changes which take place in the local environment in which the prosthesis is first implanted. The initial local environment, free from metal, polyethylene or acrylic cement particles, does not always remain 'clean'. Debris, arising from either the articulating surfaces, the concavity of the plastic liner, the Morse taper locking mechanism, the metal-backed shell of the cemented acetabular liner, the screws reinforcing the acetabular component, the porous cup, or the stem surface, scratches the 'soft' titanium alloy head, initiating in that manner a third-body wear process. ${ }^{4,8}$

It is the relatively greater 'softness' of the titanium alloy which is responsible for the higher rate of failure of these prostheses. Heads made of 'harder' metal, such as cobalt-chrome, are more difficult to scratch, and therefore less likely to generate harmful debris.

We have speculated that uncemented titanium implants may be capable of creating a similar environment and produce comparable radiological conditions. Movement between the uncemented titanium stem and the femoral cortex can 'scratch' the metal, and produce metal debris which travels to the articulation and initiates the thirdbody wear process. This may be one of the several possible explanations for the reported presence of lytic lesions in a certain percentage of uncemented total hip arthroplasties.

My own experiences have forced me to remain concerned over the use of titanium in total hip arthroplasty. The fact that there is an increase in premalignant and chromosomal changes in tissue in which metallosis forms, increases my preoccupation with titanium alloys. 9

To limit our concern regarding the use of titanium alloys only for cemented arthroplasties may prove to be a mistake. The concerns should be extended also to those which are not cemented.

\section{A. SARMIENTO, MD \\ Coral Gables}

Florida, USA.

1. Bowditch M, Villar R. Is titanium so bad? Medium-term outcome of cemented titanium stems. J Bone Joint Surg [Br] 2001;83-B:680-5.

2. Sarmiento A, Zych GA, Latta LL, Tarr RR. Clinical experiences with a titanium alloy hip prosthesis: a posterior approach. Clin Orthop 1979;144:166-173.

3. Sarmiento A, Natarajan V, Gruen T, McMahon M. Radiographic performance of two different total hip cemented arthroplasties. Orthop Clin North Am 1988;19:505-15.

4. McKellop H, Rusland T, Ebramzadeh E, Sarmiento A. Wear of titanium- 6 alloys in the laboratory and in retrieved human replacements. In: Brunette DM, et al. Titanium in medicine. Springer, 2001:747-70.

5. Sarmiento A, Ebramzadeh E, Gogan W, McKellop H. Total hip arthroplasty with cement: a long-term radiological analysis in patients who are older than 50 and younger than 50 years. J Bone Joint Surg [Am] 1990;72-A:1470-6.

6. Ebramzadeh E, Sarmiento A, McKellop H, Llinas A, Gogan M. The cement mantle in total hip arthroplasty: analysis of long-term radiographic results. J Bone Joint Surg [Am] 1994;76-A:77-87.

7. Sarmiento A, Ebramzadeh E, Norman P, Llinas A, McKellop H. The stainless steel and titanium alloy femoral prostheses. In: G. Finerman, et al, Total hip outcomes. Edinburgh, etc. Churchill Livingstone 1998.

8. McKellop HA, Sarmiento A, Schwinn CP, Ebramzadeh E. In vivo wear of titanium total hip prosthesis. J Bone Joint Surg [Am] 1990;72-A:512-7.

9. Case CP, Langkamer VG, Howell RT. Preliminary observations on possible premalignant changes in bone marrow adjacent to worn total hip arthroplasty implants. Clin Orthop 1996:329 Suppl:269-79. 


\section{Author's reply:}

Sir,

We were interested to read Dr Sarmiento's letter of his detailed experience of titanium implants. However, we also note that his concern with his personal experience of a titanium alloy prosthesis relates to the use of a monoblock design. We understand that the implant was modified to accommodate a modular cobaltchrome head, but that the results of this component have not as yet been documented. That was, of course, the entire purpose of our own submission which concerns a modular titanium alloy prosthesis.

Before undertaking our study, we were fully aware of the concerns surrounding cemented titanium prostheses. That is why our survival of $97 \%$ at a mean of 7.5 years is a surprisingly attractive result, and we felt deserved wiser dissemination. Time will no doubt tell if we can do better, worse, or the same as Dr Sarmiento. Those who read our submission in detail will detect a note of caution.

R. VILLAR, FRCS

Cambridge Hip and Knee Unit

Cambridge, UK.

\section{Should slipped capital femoral epiphysis (SCFE), a misnomer, be renamed as idiopathic capital femoral physiolysis (ICFP)}

\section{Sir,}

Slipped capital femoral epiphysis (SCFE) is a little understood condition of the hip. For more than a century it has been awaiting an appropriate name. 'slipped capital femoral epiphysis', 'epiphysiolisthesis', 'epiphysiolysis' and other terms used to describe this condition, are misnomers because they are based on the radiological appearance of the epiphysis in relation to the neck of the femur. Looks, however, are deceptive. The apparent displacement of an object based on a change in the position from which it is viewed is called radiographic parallax. For example, on radiographs, the head of the femur looks as if it has moved posteroinferiorly, giving the appearance of a varus slip. Three-dimensional CT has shown, however, that the head remains in the acetabulum, does not slip and is not affected by lysis. ${ }^{2}$

The exact cause of this condition is not known, but the site of the lesion is the growth plate. ${ }^{3}$ This is not only weakened because of the alterations in the chondrocytic maturation and endochondral ossification but is also widened. The width can be as much as two to three times the normal. ${ }^{4}$ Since the prime site of the problem is the zone of the hypertrophy in the growth plate, a good defining word is 'physiolysis'. To differentiate the condition from physiolysis occurring at other places, it is appropriate to call it 'idiopathic capital femoral physiolysis' (ICFP).

A precise descriptive name is important for the correct understanding of a condition; a misnomer alters the perception of the problem. I hope therefore to generate discussion to improve the accuracy of the terminology. I recommend replacing 'slipped capital femoral epiphysis' with the correct term 'idiopathic capital femoral physiolysis'.

K. KUMAR, MD

Baltimore, USA.

1. Nguyen D, Morrissy RT. Slipped capital femoral epiphysis: rationale for the technique of percutaneous in situ fixation. J Pediatr Orthop 1990;10:341-6.

2. Kordelle J, Richolt JA, Millis M, Jolesz FA, Kikinis R. Development of the acetabulum in patients with slipped capital femoral epiphysis: a three-dimensional analysis based on computed tomography. J Pediatr Orthop 2001;21:174-8.
3. Howorth B. Slipping of the capital femoral epiphysis: pathology. Clin Orthop 1966;48:33-48.

4. Ippolito E, Mickelson MR, Ponseti IV. A histochemical study of slipped capital femoral epiphysis. J Bone Joint Surg [Am] 1981;63-A:1109-13.

\section{Supracondylar extension fracture of the humerus in children}

Sir,

I read with interest the article by Chen et al $^{1}$ in the August 2001 issue entitled 'Supracondylar extension fracture of the humerus in children'. The authors state that closed reduction and casting with the elbow in full extension are superior to reduction and casting in flexion. This may also be superior or at least as good as the more common Western treatment of reduction and pinning. Since 1969 I have used extension treatment for displaced supracondylar fractures of the elbow in children ${ }^{2-4}$ as described by Chen et al. The only difference is that I use a shoulder spica to hold the extended upper limb at $90^{\circ}$ of forward flexion. This provides more stability to the site of the fracture and the elevation diminishes the swelling. The children are quite comfortable in this because the shoulder spica prevents the upper limb from swinging about freely. The valgus angle of the elbow can easily be adjusted with the elbow in full extension. I also mould it behind the elbow.

Posterior displacement of the distal fragment corrects itself with growth. If there is any mild rotary displacement, it is hidden by the immense rotation of the shoulder. The posterior tilting is sometimes not fully corrected by growth, but it has never been noticed by any of the parents or children whom I have treated. There has never been any varus or valgus deformities, and there was always a return to a full range of movement. There were no problems with pinning the elbow, such as ulnar neuritis or pintrack infection.

I began doing this before a $\mathrm{C}$-arm was available. Even when pinning the elbow, most orthopaedic surgeons still flex the elbow somewhat afterwards. This, however, diminishes venous return.

M. ALTCHEK, MD

Middletown, NY, USA.

1. Chen RS, Liu CB, Lin XS, et al. Supracondylar extension fracture of the humerus in children. J Bone Joint Surg [Br] 2001;83-B:883-7.

2. Altchek M. Treating displaced supracondylar fractures of the humerus in children. Orthop Rev 1979;8:31-7.

3. Altchek M. Letter to the Editor. Supracondylar fractures of the humerus. J Pediatr Orthop 1983.

4. Altchek M. Letter to the Editor. Management of displaced extension type supracondylar fractures of the humerus in children. J Bone Joint Surg [Am] 1989;71:788.

\section{Author's reply:}

Sir,

I thank Dr Altchek for his letter on supracondylar extension fracture of the humerus in children. He has used extension treatment since 1969 in basically the same way as our method. He also uses an additional shoulder spica to elevate the upper limb. We also used this method before we undertook our double-blind randomly comparative study.

I also accept that the shoulder spica would theoretically have some advantages, although there were no problems in our series of children treated without it.

\section{R. S. CHEN, MD}

Shenzhen

People's Republic of China. 